Research Article

\title{
Study on Soil-Water Characteristics of Expansive Soil under the Dry-Wet Cycle and Freeze-Thaw Cycle considering Volumetric Strain
}

\author{
Lisi Niu $\mathbb{D}^{1},{ }^{1}$ Aijun Zhang $\mathbb{D}^{1,2}$ Jiamin Zhao, ${ }^{3}$ Wenyuan Ren $\mathbb{D}^{1,2}$ Yuguo Wang, \\ and Zhichao Liang ${ }^{1}$ \\ ${ }^{1}$ College of Water Resources and Architectural Engineering, Northwest A\&F University, Yangling, Shaanxi 712100, China \\ ${ }^{2}$ Key Laboratory of Agricultural Soil and Water Engineering in Arid and Semiarid Areas, Ministry of Education, \\ Northwest A\&F University, Yangling, Shaanxi 712100, China \\ ${ }^{3}$ Gansu Institute of Water and Hydropower Engineering Investigation Design and Research Co., Ltd., Gansu, \\ Lanzhou 730000, China \\ Correspondence should be addressed to Wenyuan Ren; wenyuange304@nwsuaf.edu.cn
}

Received 10 December 2020; Revised 29 December 2020; Accepted 2 January 2021; Published 30 January 2021

Academic Editor: Song-He Wang

Copyright $\odot 2021$ Lisi Niu et al. This is an open access article distributed under the Creative Commons Attribution License, which permits unrestricted use, distribution, and reproduction in any medium, provided the original work is properly cited.

\begin{abstract}
This paper targets the expansive soils in Heilongjiang and Ankang to explore the influence of initial dry density, dry-wet cycle, and freeze-thaw cycle on the soil-water characteristics. The centrifuge method was used to obtain the soil-water characteristic curves (SWCCs) with different conditions. The volumetric strain of SWCC was modified based on the shrinkage test, and the corresponding fitting equations considering different factors were established. The results show that the volumetric water content is modified to consider the volume shrinkage effect of expansive soil, and the modification is more obvious in the high matric suction range. The smaller the initial dry density is, the worse the water-holding capacity of the sample is, and the smaller the air intake value is. The greater the time of the dry-wet cycle is, the greater the saturated volumetric water content of the sample is, and the corresponding water-holding capacity is significantly reduced. When the dry-wet cycle increases to a certain extent, the structure becomes stable. With the increase of the freeze-thaw cycle, the saturated volumetric water content first decreases and then increases. Similarly, after several times of the freeze-thaw cycle, the structure is basically stable. The fitted Gardner model equations under different conditions were proved to be able to describe the SWCCs of the two targeted expansive soils.
\end{abstract}

\section{Introduction}

Soil-water characteristic curve (SWCC) reflects the relationship between water content, degree of saturation, and matric suction of unsaturated soil. The commonly used test methods include the pressure plate method, filter paper method, centrifuge method, and tensiometer method. The centrifuge method is widely used because of its simple operation, short time usage, and the ability to measure the SWCC under high matric suctions [1-5]. As a kind of soil with high clay content and a large number of hydrophilic minerals, expansive soil has a series of special properties such as strong water sensitivity, swelling, and shrinkage. It is one of the most problematic kinds of soil to deal with in the engineering field and has been a hot research topic of theoretical research on unsaturated soil.

Heilongjiang expansive soil is a kind of lacustrine sedimentary soft clay with expansibility, dispersibility, frost heave, and high soluble salt content. It is black-brown, which is obviously different from the red-brown expansive soil in southern China. Its existence has caused great hazards such as canal slope sliding, road deformation, and house cracking, which seriously affects the operation safety of the corresponding projects. The expansive soil in Ankang hilly area has a subtropical continental monsoon climate. The swelling and shrinkage caused by seasonal rainfall led to a large area 
of cracks on the ground. According to the statistics of the meteorological station, the extreme minimum temperature in this area is $-9.7^{\circ} \mathrm{C}$, there is a slight freeze from December to February, and the construction in winter is vulnerable to the seasonal freeze-thaw effect. Therefore, it is very important to study the unsaturated soil characteristics of the above two special soils, especially the soil-water characteristics under the complex conditions of dry-wet and freezethaw.

At present, in addition to the research on deformation and strength [6,7] and solidification improvement [8-10] of expansive soil, some achievements have been made in the aspect of the soil-water characteristics [11,12]. Ito and Azam [13] pointed out the swell-shrink path is S-shaped and indicated that it is more accurate to express SWCC by gravimetric water content than by saturation. Puppala et al. [14] prepared expansive soils with different stabilizers and established the Fredlund and Xing model related to the basic soil parameters. Subsequently, Puppala et al. [15] explored the characteristics of physical and mineralogical, three-dimensional free swell and shrinkage for five expansive soils in America. Elkady et al. [16] analyzed the influence of net vertical stress on the SWCC of lime-treated expansive clay, especially in its saturation and the air entry value. Han and Vanapalli [17] introduced a normalized function to represent the nonlinear stiffness, strength, and suction of unsaturated soil in the low suction range and made a good prediction for different soil structures, anisotropy, hydraulic hysteresis, and other factors.

In combination with the study of characteristics of volumetric strain, Zhou and Kong [18] explored the interaction between the volumetric strain and soil-water characteristics of expansive soil by using the dehumidification test and constructed the equation of volumetric strain under the suction. Zou et al. $[19,20]$ proposed a more reasonable volume correction equation through dehumidification tests and shrinkage tests under different initial dry densities. Ma et al. [21] used nuclear magnetic resonance (NMR) technology to study the change law of water content in the drywet cycle and explained the change mechanism of the pore in SWCC. Whereafter, some scholars studied SWCC under complex conditions such as dry-wet cycle and freeze-thaw cycle [22-29]. It can be seen that these studies are aimed at the expansive soil in a particular area, and the SWCCs of expansive soils in different areas have different laws under the external conditions such as dry-wet cycle and freezethaw cycle. At present, the research on soil-water characteristics of expansive soil in Heilongjiang and Ankang is relatively less, especially in the complex conditions of drywet and freeze-thaw cycles.

In this paper, based on the expansion project in Heilongjiang and airport project in Ankang, the black-brown expansive soil in Heilongjiang and yellow-brown expansive soil in Ankang are taken as the research objects. The SWCCs under different dry densities and time of dry-wet and freezethaw cycle are measured by the high-speed refrigerated centrifuge method. The influence of various factors on the soil-water characteristics of expansive soil is explored, and the equation considering volume correction is put forward and verified by the tests. It provides some theoretical basis and significance for the study of the constitutive model for the unsaturated expansive soil under the rainfall infiltration in Songnen plain area and Ankang hilly area.

\section{Materials and Methods}

2.1. Test Sample and Preparation. The test soil is taken from the Wunan trunk canal section of the expansion project in Heilongjiang and the construction area of the airport project in Ankang, Shaanxi. The depth of Heilongjiang (for short "HLJ") soil is $0.4 \mathrm{~m}-6 \mathrm{~m}$, which is black-brown. The depth of Ankang (for short "AK") soil is $1.5 \mathrm{~m}-7.5 \mathrm{~m}$, which is tawny. The two expansive soils are shown in Figure 1, and the corresponding physical indexes and mineral compositions are shown in Table 1.

In addition, the HLJ soil belongs to low liquid limit clay (CL), which is comprehensively identified as dispersed soil in laboratory tests. The total soluble salt content is determined to be $4.9 \mathrm{~g} / \mathrm{kg}$; that is, the HLJ soil is a special expansive soil of both dispersive soil and saline soil. The AK soil belongs to high liquid limit clay $(\mathrm{CH})$, its maximum dry density is $1.68 \mathrm{~g} / \mathrm{cm}^{3}$, and the optimal water content is $22.2 \%$.

The samples in this paper are all remolded samples with a target water content of 15\%. The designed dry densities of HLJ soil samples are $1.45 \mathrm{~g} / \mathrm{cm}^{3}, 1.53 \mathrm{~g} / \mathrm{cm}^{3}, 1.58 \mathrm{~g} / \mathrm{cm}^{3}$, and $1.63 \mathrm{~g} / \mathrm{cm}^{3}$. The shrinkage and SWCC tests are carried out under each dry density. When the dry density is $1.45 \mathrm{~g} / \mathrm{cm}^{3}$, the SWCC tests are conducted under 1, 3, 5, and 7 times of dry-wet cycle. The designed dry densities of AK soil samples are $1.39 \mathrm{~g} / \mathrm{cm}^{3}, 1.47 \mathrm{~g} / \mathrm{cm}^{3}, 1.55 \mathrm{~g} / \mathrm{cm}^{3}$, and $1.63 \mathrm{~g} / \mathrm{cm}^{3}$. Similarly, the shrinkage and SWCC tests are carried out under each dry density. When the dry density is $1.47 \mathrm{~g} / \mathrm{cm}^{3}$, the SWCC tests are performed under 1, 3, 5, and 7 times of dry-wet cycle and freeze-thaw cycle. To sum up, a total of 20 centrifuge samples and 8 shrinkage samples are prepared. The shrinkage sample is a ring cutter sample with a diameter of $6.18 \mathrm{~cm}$, a height of $2 \mathrm{~cm}$, and a volume of $60 \mathrm{~cm}^{3}$, which is made by pressing soil at one time. The centrifuge sample is a cylindrical sample with an area of $20 \mathrm{~cm}^{2}$, a height of $5 \mathrm{~cm}$, and a volume of $100 \mathrm{~cm}^{3}$, which is prepared by stamping in layers. The specific process of sample preparation is as follows:

(1) The air-dried soil was crushed and sieved by $2 \mathrm{~mm}$; then, the air-dried water content of the soil was measured. The required water was calculated according to the quality of air-dried soil and the target water content. Then, a pot was evenly sprayed by layer, and the soil was sealed with fresh-keeping film for more than 24 hours.

(2) The prepared sample was evenly stirred, and the actual water content and the error between it and the target water content were measured. The corresponding quality sample was weighed according to the sample volume and designed dry density.

(3) For the samples with the dry-wet cycle, after humidifying with a rubber dropper to the designed water content, the samples were wrapped with fresh- 


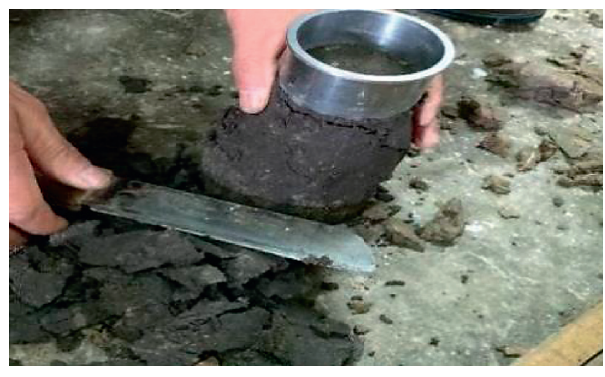

(a)

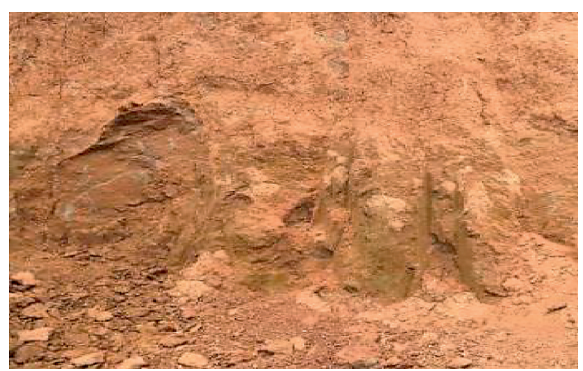

(b)

Figure 1: Expansive soil (a) in Heilongjiang (b) in Ankang.

TABle 1: Physical indexes and mineral compositions of the sample.

\begin{tabular}{|c|c|c|c|c|c|c|c|c|c|c|c|c|}
\hline \multicolumn{13}{|c|}{ Physical indexes of sample } \\
\hline \multirow{2}{*}{$\begin{array}{l}\text { Soil } \\
\text { sample }\end{array}$} & \multirow{2}{*}{$\begin{array}{l}\text { Specific } \\
\text { gravity }\end{array}$} & \multirow{2}{*}{$\begin{array}{c}\text { Dry } \\
\text { density } \\
\left(\mathrm{g} / \mathrm{cm}^{3}\right)\end{array}$} & \multirow{2}{*}{$\begin{array}{c}\text { Free } \\
\text { swelling } \\
\text { rate }(\%)\end{array}$} & \multirow{2}{*}{$\begin{array}{c}\text { Liquid } \\
\text { limit (\%) }\end{array}$} & \multirow{2}{*}{$\begin{array}{l}\text { Plastic } \\
\text { limit } \\
(\%)\end{array}$} & \multirow{2}{*}{$\begin{array}{c}\text { Plasticity } \\
\text { index }\end{array}$} & \multicolumn{3}{|c|}{ Grain composition (\%) } & \multirow{2}{*}{\multicolumn{3}{|c|}{ Soil classification }} \\
\hline & & & & & & & Sand & Silt & Clay & & & \\
\hline HLJ & 2.69 & 1.68 & 48 & 33 & 15.5 & 17.5 & 19 & 50 & 31 & \multicolumn{3}{|c|}{$\mathrm{CL}$} \\
\hline $\mathrm{AK}$ & 2.71 & 1.66 & 60 & 47.1 & 24.8 & 22.3 & 1.2 & 37.8 & 61 & & $\mathrm{CH}$ & \\
\hline \multicolumn{13}{|c|}{ Mineral compositions of sample } \\
\hline \multirow[b]{2}{*}{$\begin{array}{l}\text { Soil } \\
\text { sample }\end{array}$} & \multicolumn{4}{|c|}{ Non-clay mineral content (\%) } & \multicolumn{5}{|c|}{ Clay mineral content $(\%)$} & \multirow{2}{*}{$\begin{array}{c}\text { Ratio of } \\
\text { illite and } \\
\text { smectite } \\
(\%)\end{array}$} & \multicolumn{2}{|c|}{$\begin{array}{c}\text { Estimate of } \\
\text { total soil (\%) }\end{array}$} \\
\hline & Quartz & $\begin{array}{l}\text { Potash } \\
\text { feldspar }\end{array}$ & Plagioclase & Dolomite & Others & $\begin{array}{l}\text { Mixed layer } \\
\text { of illite and } \\
\text { smectite }\end{array}$ & Illite & Kaolinite & Chlorite & & Illite & Smectite \\
\hline HLJ & 29.4 & 5.8 & 13.7 & 2.1 & 19.9 & 15.1 & 7.6 & 2.0 & 4.4 & 20 & 10.6 & 12.1 \\
\hline $\mathrm{AK}$ & 26.7 & 2.7 & 9.6 & 4.9 & 1.6 & 43.6 & 8.7 & 2.2 & 0 & 60 & 34.9 & 17.4 \\
\hline
\end{tabular}

keeping film and placed in the moisturizing tank for 24 hours and then dried to the initial water content in the oven at a constant temperature of $60^{\circ} \mathrm{C}$. Thus, one dry-wet cycle was completed, and the samples with $1,3,5$, and 7 times of dry-wet cycle were completed in turn.

(4) For the sample with the freeze-thaw cycle, it was placed in a freezer with a constant temperature of $-10^{\circ} \mathrm{C}$ for 12 hours (the extreme minimum temperature is $-9.7^{\circ} \mathrm{C}$ in Ankang), and then the sample was placed in an incubator at $20^{\circ} \mathrm{C}$ for 12 hours to complete one freeze-thaw cycle. The samples with 1 , 3,5 , and 7 times of freeze-thaw cycle were successively completed. The prepared samples are wrapped and placed in the moisturizing tank for standby.

2.2. Test Equipment and Operation. The SWCC test was measured by the centrifuge method. The test equipment is a CR21R high-speed thermostatic refrigerated centrifuge (Figure 2) produced by HITACH company in Japan. Its maximum speed is $21000 \mathrm{r} / \mathrm{min}$, the maximum relative centrifugal force is $11000 \mathrm{~g}$, and the maximum capacity is $250 \mathrm{~mL}$. The principle is to convert the centrifugal force at different rotating speeds into the corresponding matric suction and measure the water content under each

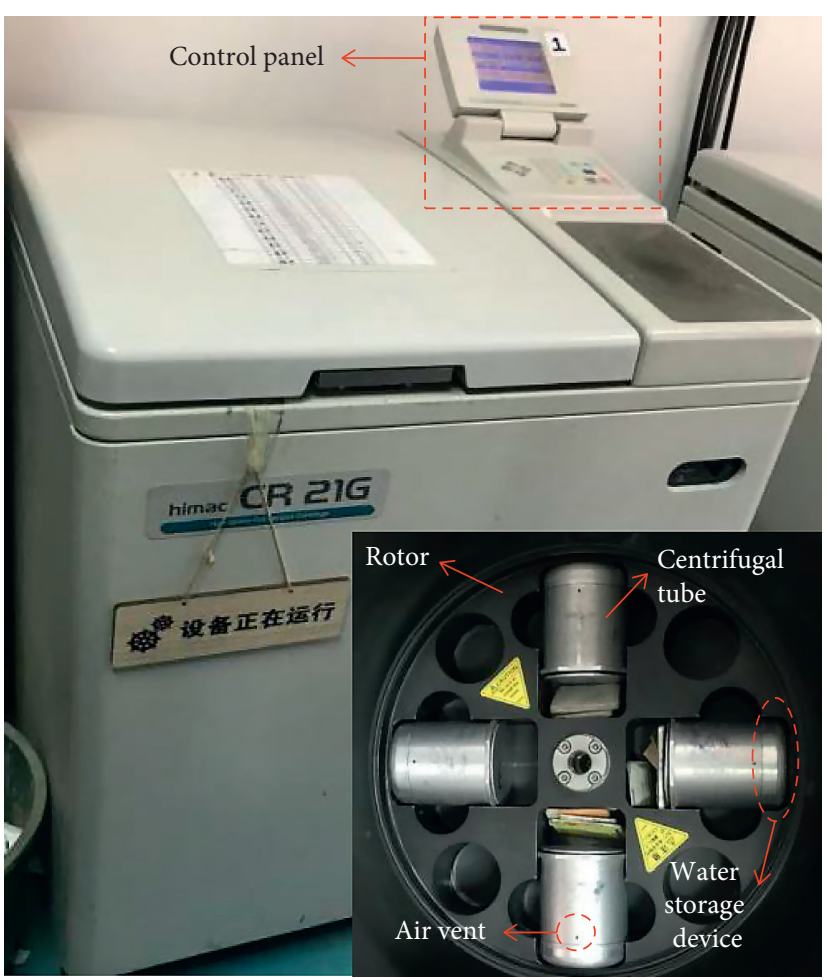

FIGURE 2: High-speed thermostatic refrigerated centrifuge. 
centrifugal force to obtain the SWCC of the sample. The matric suction levels in the test are $1 \mathrm{kPa}, 5 \mathrm{kPa}, 10 \mathrm{kPa}$, $20 \mathrm{kPa}, 40 \mathrm{kPa}, 60 \mathrm{kPa}, 80 \mathrm{kPa}, 100 \mathrm{kPa}, 200 \mathrm{kPa}, 400 \mathrm{kPa}$, $600 \mathrm{kPa}$, and $800 \mathrm{kPa}$. The specific steps are as follows:

(1) The sample was taken out of the moisturizing tank. Filter papers and porous stones were padded on the upper and lower surfaces. The upper and lower ends of the samples were fixed with rubber bands, and the samples were saturated with vacuum pumping.

(2) The porous plate was aligned with the permeable hole at the bottom of the centrifuge tube, and the weight of the centrifuge tube was measured. The knife edge of the ring cutter was mounted upward into the centrifugal tube, and the mass of the centrifuge tube was leveled on the basis of the weighed quality to make the difference less than $0.5 \mathrm{~g}$.

(3) On the premise that the centrifuge rotor rotated flexibly, the water storage device of the centrifuge tube was put into the centrifuge head closed to the outer edge and the air vent upward. Then, the lid was tightened, the door was closed, and the speed, time, and temperature were set to operate the centrifuge.

(4) After balancing at each rotating speed, the centrifuge tube was taken to weigh the mass, and the radial and vertical shrinkage of the sample was measured with an electronic vernier caliper. Then, the centrifuge tube was leveled again, and the next matric suction was carried out according to step (3).

The shrinkage test of expansive soil is used to measure the vertical shrinkage coefficient of the sample in the process of natural air drying, and the shrinkage curves are obtained under different initial dry densities, which are used to modify the SWCC considering the volumetric strain of the sample. The shrinkage test is carried out with a shrinkage instrument. The prepared sample was pushed out of the ring cutter, placed on the porous plate, weighed, and tested in an indoor environment not higher than $30^{\circ} \mathrm{C}$. The vertical dial indicator was recorded every hour, and the mass of the whole set of device and sample was weighed. After 48 hours, the dial indicator was recorded every 6 hours until it remained unchanged for 2 periods of time. The sample was taken out and placed into the oven at $105^{\circ} \mathrm{C}$ for more than 8 hours. Then, the quality of the dry sample was weighed and the volume of the sample was determined using the wax sealing method; thus, the water content and linear shrinkage ratio were deduced.

\section{Correction Method of SWCC considering Volumetric Strain}

3.1. Shrinkage Test Results. Figure 3 shows the relationships between vertical linear shrinkage ratio and water content of two expansive soils under different initial dry densities. It can be seen that (1) the vertical shrinkage ratio of the two expansive soils can be divided into three stages: linear shrinkage, transitional shrinkage, and shrinkage stability with the increase of water content of the sample. In the linear

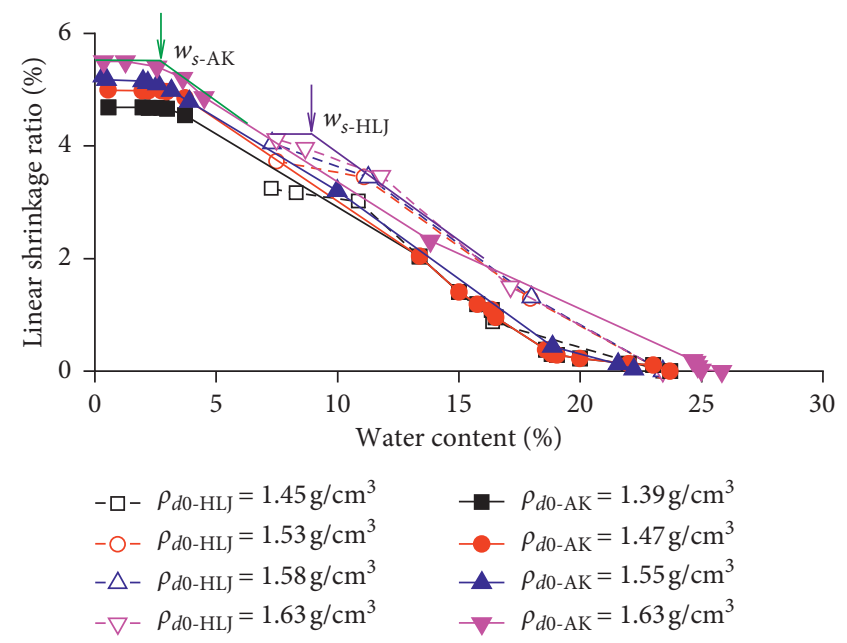

Figure 3: The relationships between vertical linear shrinkage ratio and water content of two expansive soils under different initial dry densities.

shrinkage stage (stage I), with the continuous discharge of pore water and air in the sample, the water content decreases, the soil particles gradually close to each other, and the sample gradually shrinks. In the transitional shrinkage stage (stage II), when the water content decreases to a certain extent, the connection between soil particles is relatively close, and the shrinkage of soil is slower and slower. In the shrinkage stability stage (stage III), the change of soil internal stress caused by the decrease of water content is difficult to overcome the interaction between soil particles, and the connection between soil particles tends to be stable. By this time, the decrease of water content no longer causes obvious shrinkage of samples.

(2) Both linear shrinkage ratios of the two expansive soils increase gradually with the increase of initial dry density, but the shrinkage limit $\left(w_{s}\right)$ under different initial dry densities of the same expansive soil is approximately the same. Moreover, the shrinkage limit of AK soil $\left(w_{s-\mathrm{AK}}\right)$ is smaller than that of HLJ soil $\left(w_{s-\mathrm{HLJ}}\right)$, indicating that AK expansive soil has a stronger swell-shrink characteristic, which is consistent with the higher free swelling rate and clay minerals of AK expansive soil in Table 1.

After the SWCC test, the water content of the sample is greater than the shrinkage limit of the soil. Therefore, the samples are all in the first stage (that is, the linear shrinkage stage) during the whole process of the SWCC test. According to the shrinkage test, the vertical linear shrinkage $\left(\delta_{s i}\right)$ and the variation of water content $\left(w_{0}-w\right)$ can be expressed as a linear relation as follows:

$$
\delta_{Y}=\frac{\Delta Z}{Z_{0}}=\lambda_{Y}\left(w_{0}-w\right),
$$

where $\delta_{Y}$ is the vertical linear shrinkage ratio (\%); $Z_{0}$ and $\Delta Z$ are the initial height of the sample $(\mathrm{cm})$ and the height reduced by water loss at a certain time $(\mathrm{cm})$, respectively; $\lambda_{Y}$ is the vertical shrinkage coefficient of the sample, that is, the slope of the straight-line section of the shrinkage curve in 
Figure $3 ; w_{0}$ and $w$ are the initial water content of the sample and the water content at a certain time (\%), respectively.

After sorting out the shrinkage test results of HLJ and AK expansive soils under different initial dry densities, the corresponding relationships between the vertical shrinkage coefficient and the initial dry density are obtained (see Figure 4). It can be seen that the vertical shrinkage coefficient is approximately linear with the initial dry density; that is, the greater the initial dry density is, the greater the vertical shrinkage coefficient is. Comparing the two expansive soils, the vertical shrinkage coefficient of HLJ soil is larger under the same initial dry density, and it is greatly affected by the initial dry density.

The vertical shrinkage coefficient can be expressed by the initial dry density:

$$
\lambda_{Y}=A \rho_{d 0}-B
$$

where $A$ and $B$ are parameters. For the HLJ expansive soil, $A=0.334$ and $B=0.242$. For the AK expansive soil. $A=0.135$ and $B=0.032$.

3.2. Correction Method Based on the Shrinkage Test. The volumetric strain of expansive soil is rarely considered in the common SWCC model. Due to a large number of hydrophilic minerals in expansive soil, the change of water content will cause swelling and shrinkage deformation, which will affect the soil-water characteristic law of the soil. Therefore, the volumetric strain on SWCC in this paper has been modified in the SWCC test to reflect the actual situation of the sample.

At present, in terms of calculating the volumetric strain of expansive soil during the dehumidification process according to the shrinkage test of expansive soil, Zhang et al. [30] put forward that the volumetric strain can be expressed with linear shrinkage ratios in three directions when the vertical and horizontal linear shrinkage ratios were small. The expression was as follows:

$$
\frac{\Delta V}{V_{0}}=\left(\lambda_{Y}+2 \lambda_{X}\right) \Delta w
$$

where $\lambda_{X}$ is the transverse shrinkage coefficient. It can be seen that although equation (3) takes into account the linear shrinkage ratios in three directions, and the vertical shrinkage ratio can be measured, measuring accurately the transverse shrinkage ratio in the actual test is difficult to achieve.

In addition, Zhou and Kong [18] directly corrected the volume change after the SWCC test, which can be expressed as follows:

$$
\lambda_{V}=\frac{\left(\Delta V / V_{0}\right)}{\Delta w} \times 100,
$$

where $\lambda_{V}$ is the volume shrinkage coefficient of the first stage in the shrinkage test, $\Delta V$ is the volume variation before and after the SWCC test $\left(\mathrm{cm}^{3}\right), V_{0}$ is the initial volume of the sample $\left(\mathrm{cm}^{3}\right)$, and $\Delta w$ is the variation of the water content after the test (\%). However, equation (4) adopts the vertical

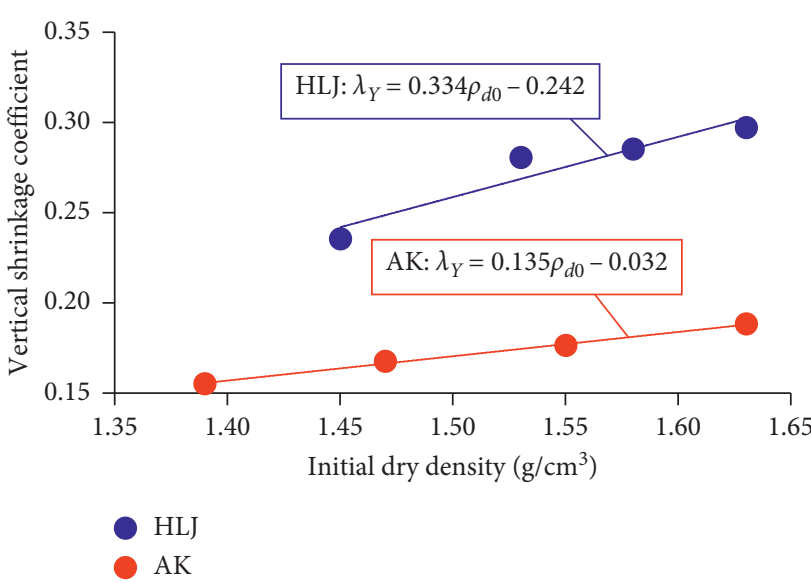

FIGURE 4: The relationships between vertical shrinkage coefficient and the initial dry density.

shrinkage ratio instead of the volume shrinkage ratio, which cannot completely reflect the essence of volume shrinkage in the process of water loss of expansive soil.

Based on the conclusion that the horizontal and vertical shrinkage coefficients are approximately equal [30], then Zou et al. [19] proposed the equation for the volume change of expansive soil with water content as follows:

$$
\frac{\Delta V}{V_{0}}=1-\left(1-\frac{\Delta Z}{Z_{0}}\right)^{3}=1-\left[1-\lambda_{Y} \Delta w\right]^{3}
$$

In this paper, the method of Zou et al. was adopted to correct. Specifically, the vertical shrinkage coefficient $\left(\lambda_{Y}\right)$ of the sample is firstly measured by shrinkage test, and then the modified volumetric water content $(\theta)$ under matrix suction $(s)$ was calculated by using equations $(5)-(8)$ in turn, so as to obtain the relationship between the modified volumetric water content and matrix suction.

$$
\begin{aligned}
e & =e_{0}-\frac{\Delta V}{V_{0}}\left(1+e_{0}\right), \\
S_{r} & =\frac{G_{s} w}{e}, \\
\theta & =\frac{S_{r} e}{1+e},
\end{aligned}
$$

where $e_{0}$ and $e$ are the initial void ratio and the void ratio at a certain time, respectively; $S_{r}$ is saturation; $G_{s}$ is specific gravity; $\theta$ is volumetric water content (\%).

\section{SWCC Test Results}

4.1. SWCCs under Different Initial Dry Densities. The curves of void ratio with matric suction under different initial dry densities of the two expansive soils are shown in Figure 5. As can be seen from Figure 5, in the process of the SWCC test, with the increase of matrix suction, the water and air in the sample are continuously discharged, and the void ratio is accompanied by a certain shrinkage. The overall variation 


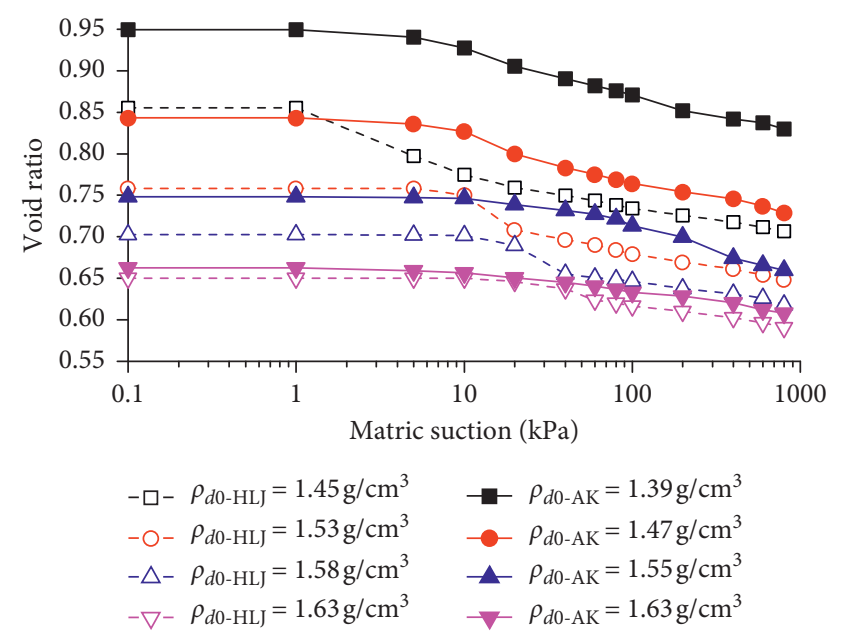

FIGURE 5: The curves of void ratio with matric suction under different initial dry densities.

trend of the AK soil curve is relatively flat. In the same expansive soil with different initial dry densities, there is no crossover phenomenon. The void ratio of the sample with lower initial dry density has a larger variation range. This is because the sample with lower dry density has larger void ratios; relatively, there are more macropores inside the sample, better permeability allowing water to pass through, and a larger variation range of water content. Therefore, the void ratio decreases more significantly with the increase of matric suction.

The SWCCs of the two expansive soils under different initial dry densities are shown in Figure 6. It can be seen that (1) the SWCCs are all inverted S-shaped. For the same expansive soil, the smaller the initial dry density is, the greater the saturated volumetric water content of the sample is, the worse the water-holding capacity is, and the smaller the air intake value is. (2) According to the shape of the curve, it can be divided into two stages: when the matric suction is less than the air intake value, the volumetric water content of the sample changes very slowly with the matric suction, and the curves under different initial dry densities intersect each other. When the matric suction is greater than the air intake value, the curve is steeper and the variation amplitude of the volumetric water content is greater. The curves tend to converge gradually with the increase of matric suction. (3) When the matric suction increases to $800 \mathrm{kPa}$, the volumetric water content of HLJ soil and AK soil under different initial dry densities is $35 \%, 37 \%, 38 \%, 37 \%$ and $43 \%, 41 \%, 41 \%, 45 \%$, respectively, which do not reach the residual water content but do not differ much from each other. If the matric suction continues to increase, the curve will show the third stage; that is, the volumetric water content of the sample will not change with the increase of matric suction. It can be concluded that the initial dry density has little influence on the residual water content of the sample. (4) Comparing the two expansive soils, the volumetric water content of $\mathrm{AK}$ soil varies greatly with matric suction, and the volumetric water content of AK soil

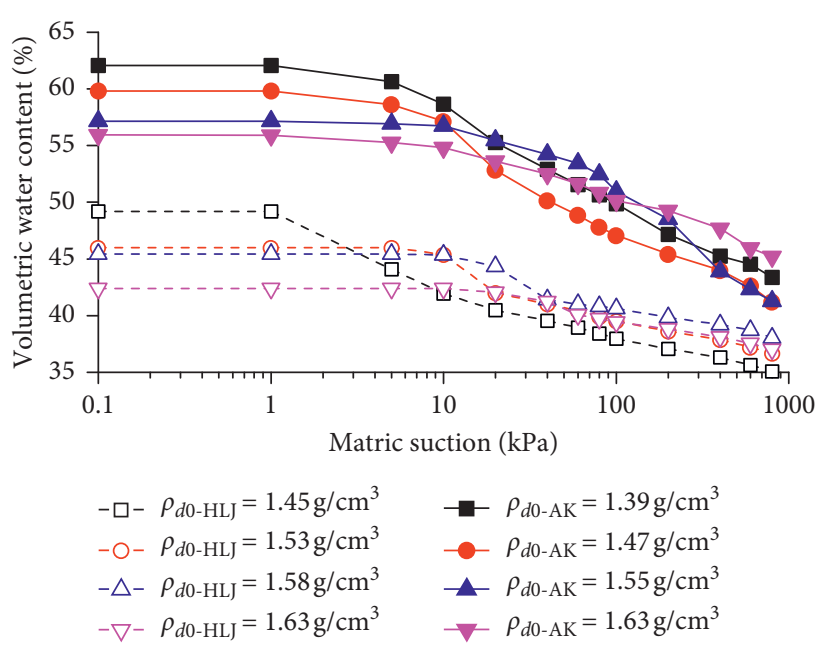

Figure 6: The SWCCs under different initial dry densities.

is much higher than that of HLJ soil under similar dry density.

This is because AK soil has high clay content and a mixed layer of illite and smectite, so its specific surface area is larger, which makes it have a higher volumetric water content under the same matric suction.

In conclusion, the SWCC can not only represent the relationship between the volumetric water content and matric suction but also further reflect the internal pores of the sample. It can be said that the influence of the initial dry density on the soil-water characteristics can be understood as a result of the varying extent of internal pores in the sample [31].

4.2. SWCCs under Different Times of Dry-Wet Cycle. The researches show that the main factors affecting the mesostructure of soil-water characteristics under the same initial dry density and volumetric water content are as follows: first, the pore compression makes structure change; second, the cement composed of soluble salts between particles is dissolved under the action of water, and then the skeleton structure changes. The modified SWCCs of the two expansive soils under the different times of dry-wet cycle $\left(N_{\mathrm{DW}}=1,3,5,7\right)$ are shown in Figure 7.

The following can be seen from Figure 7. (1) With the increase of the time of the dry-wet cycle, the saturated volumetric water content of the two kinds of expansive soil samples increases, but the water-holding capacity of the samples decreases obviously. (2) With the increase of the time of dry-wet cycle, the air intake value of the HLJ soil sample does not differ much, but that of the AK soil sample gradually decreases. (3) In the low matric suction region, the SWCCs for the same expansive soil under different times of dry-wet cycle all intersect. With the increase of matric suction, the curves converge in the high matric suction region, indicating that the dry-wet cycle has little influence on the residual volumetric water content. (4) The SWCCs of the 3 and 5 times of dry-wet cycle for HLJ soil basically coincide. The curves of the 3 and 5 times for AK soil have a 


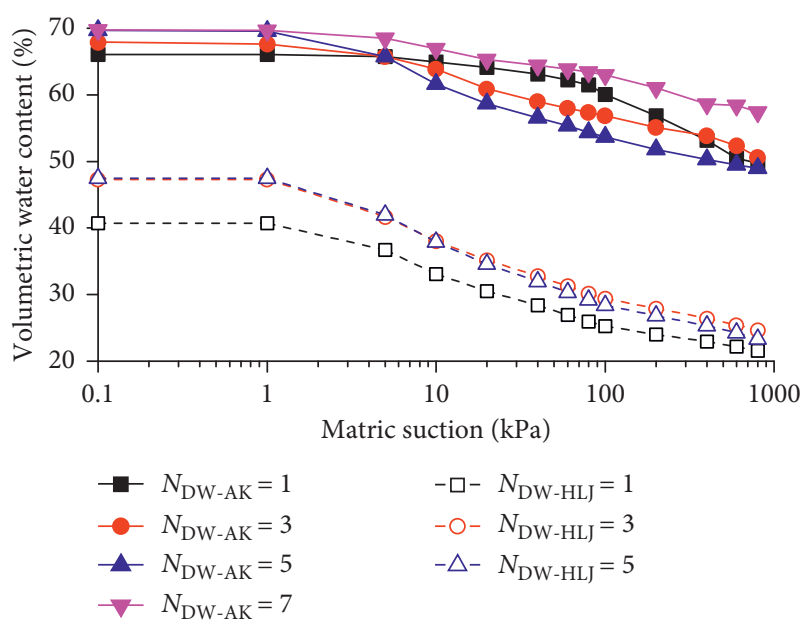

FIgURE 7: The SWCCs under different times of the dry-wet cycle.

similar trend, and the saturated volumetric water content of the samples of the 5 and 7 times is basically the same. This indicates that with the increase of the time of the dry-wet cycle, the influence of the dry-wet cycle decreases gradually, and at this time, the structure of the sample gradually tends to be stable.

To sum up, this is because the sample expands in water absorption in the process of humidification process, and the soil particles rearrange to form a new structure. After drying, the water content of the sample decreases, and the structure is damaged, which makes the sample shrink and produce cracks. In addition, the HLJ soil sample is salinized soil, and the dissolution of crystals soluble salt during humidification leads to the continuation of small pores into large pores, accelerating the formation of cracks. As the dry-wet cycle is repeated, the cracks of the sample increase, and the structure of the final sample tends to be stable and cannot recover to the initial structure, thus affecting its water-holding capacity, residual water content, and air intake value.

4.3. SWCCs under Different Times of Freeze-Thaw Cycle. Figure 8 shows the SWCCs for AK soil under different times of freeze-thaw cycle $\left(N_{\mathrm{FT}}=1,3,5,7\right)$. It shows the following. (1) The freeze-thaw cycle has a significant impact on the SWCC of AK soil. The saturated volumetric water contents of the samples are all lower than that of the sample with one freeze-thaw cycle, and that of the sample with 3 times freezethaw cycle decreases by $8 \%$. However, when the time of the freeze-thaw cycle continues to increase, the saturated volumetric water content of the sample increases. The SWCCs of 5 and 7 times of freeze-thaw cycle basically coincide, and the saturated volumetric water content on the whole first decreases and then increases. (2) With the increase of the time of the freeze-thaw cycle, the water-holding capacity and air intake value also decrease slightly, but the difference is little. These are all the results of the influence of the freezethaw cycle on the internal pore structure of samples. During the process of the freeze-thaw cycle, changes such as phase transition and migration of water will occur inside the expansive soil, which will affect the internal microstructure

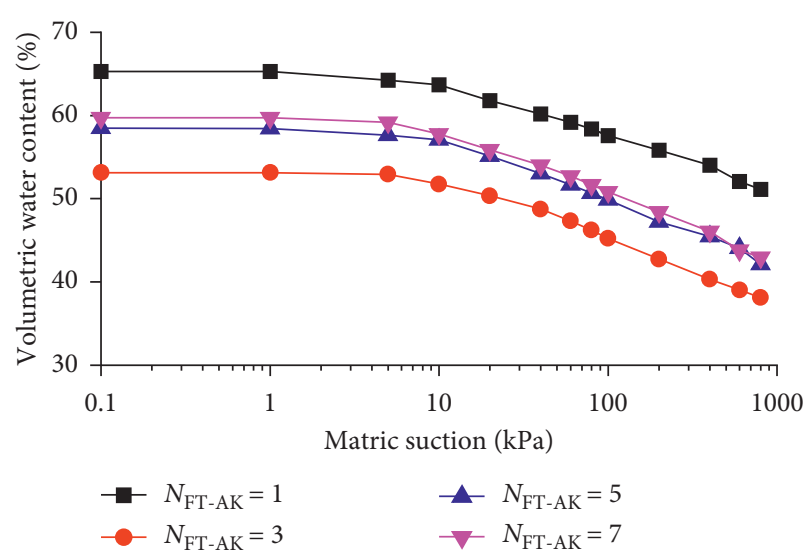

Figure 8: The SWCCs for Ankang expansive soil under different times of the freeze-thaw cycle.

of the expansive soil. (3) When the time of the freeze-thaw cycle is less $\left(N_{\mathrm{FT}} \leq 1\right)$, the internal pores of the samples are not damaged obviously. Relatively speaking, the air intake values of the 1 time and the 3 times of freeze-thaw cycle are quite different. Nevertheless, the air intake values and saturated and residual volumetric water contents of the 5 times and the 7 times of freeze-thaw cycle are basically the same, which further explains that with the increase of the time of the freeze-thaw cycle, the porosity inside the sample becomes more homogeneous and its structure becomes stable gradually.

\section{SWCC Fitting}

Based on the test results, many scholars have proposed SWCC models with different parameters to characterize the soil-water characteristics of unsaturated soil. The commonly used SWCC models are the Gardner model, van Genuchten model, and Fredlund \& Xing model.

Gardner [32] proposed a simple SWCC model with three parameters:

$$
\theta=\theta_{r}+\frac{\theta_{s}-\theta_{r}}{1+(s / \alpha)^{q}}
$$

where $\theta$ is the volumetric water content (\%); $\theta_{s}$ is the saturated volumetric water content (\%); $\theta_{r}$ is the residual volumetric water content (\%); $s$ is the matrix suction $(\mathrm{kPa}) ; \alpha$ and $q$ are the fitting parameters.

Van Genuchten [33] found that the model based on Mualem expression is more consistent with the test results than the equation based on Burdine theory. The corresponding SWCC model was as follows:

$$
\theta=\theta_{r}+\frac{\theta_{s}-\theta_{r}}{\left[1+(\alpha s)^{q}\right]^{n}}
$$

where $\alpha, q$, and $n$ are fitting parameters, and $n=1-1 / q$.

Based on the assumption that the shape of SWCC depends on the distribution of soil pores, Fredlund and Xing [34] put forward a SWCC model suitable for sand, silt, and clay in the whole matric suction range: 
TABLE 2: Fitting parameters of SWCC with different initial dry densities of HLJ soil.

\begin{tabular}{lccccccccccc}
\hline \multirow{2}{*}{ Initial dry density $\left(\mathrm{g} / \mathrm{cm}^{3}\right)$} & \multicolumn{3}{c}{ Gardner model } & \multicolumn{3}{c}{ Van Genuchten model } & \multicolumn{3}{c}{ Fredlund \& Xing model } \\
& $\alpha$ & $q$ & $\theta_{r}(\%)$ & $\alpha$ & $q$ & $n$ & $\theta_{r}(\%)$ & $a$ & $p$ & $m$ & $\theta_{r}(\%)$ \\
\hline 1.45 & 12.4293 & 0.7775 & 35.30 & 1.0509 & 17.6158 & 0.0113 & 30.6 & 1.7565 & 1.7567 & 0.1390 & 35.16 \\
1.53 & 38.4611 & 1.1673 & 37.01 & 0.1327 & 32.9015 & 0.0104 & 34.73 & 9.3536 & 2.8059 & 0.0857 & 14.41 \\
1.58 & 52.2093 & 1.5942 & 37.82 & 0.0660 & 20.3720 & 0.0229 & 36.18 & 18.3601 & 3.3389 & 0.0745 & 2.11 \\
1.63 & 87.1866 & 1.5780 & 36.11 & 0.0370 & 4.2571 & 0.0966 & 33.98 & 26.2025 & 2.5167 & 0.0668 & 3.27 \\
\hline
\end{tabular}

$$
\theta=\theta_{r}+\frac{\theta_{s}}{\left\{\ln \left[\mathrm{e}+(s / a)^{p}\right]\right\}^{m}},
$$

where $a, p$, and $m$ are fitting parameters.

\subsection{Model Fitting of SWCC considering the Initial dry Density.}

Three models in equations (9)-(11) are used to fit the test results of HLJ soil under different initial dry densities. The fitting parameters are shown in Table 2. It can be seen that the Gardner model has the least parameters among the three models, the residual volumetric water content is reasonable, and there are no parameters below the percentile, which is the most suitable for fitting the relationship between volumetric water content and matrix suction under different initial dry densities of expansive soil in Heilongjiang area.

Similarly, the Gardner model is used to fit the SWCC of AK soil under different initial dry densities. The test points and fitting curves using the Gardner model for two kinds of expansive soils under different initial dry densities are shown in Figure 9. It can be seen that the test points are all above and below the fitting curve, indicating that the Gardner model can better fit the soil-water characteristics of HLJ and AK expansive soils.

Figure 10 shows the relationships between the fitting parameters of the Gardner model and the initial dry density for two kinds of expansive soil samples. Obviously, the parameter $\alpha$ is greatly affected by the initial dry density. The parameter $\alpha$ of the two expansive soils both changes approximately linearly with the increase of the initial dry density, but $q$ and $\theta_{r}$ are less affected by the initial dry density, so both of them are averaged in the Gardner model presented in this paper. The linear relationship of parameter $\alpha$ expressed by initial dry density is substituted into the Gardner model expression, and the soil-water characteristic model of expansive soil considering initial dry density could be obtained as follows:

$$
\theta=\theta_{r}+\frac{\theta_{s}-\theta_{r}}{1+\left(s /\left(c \rho_{d}+d\right)\right)^{q}},
$$

where $c$ and $d$ are parameters; for HLJ soil, $\theta_{r}=36.56 \%$, $q=1.28, c=396.31$, and $d=-565.72$; for AK soil, $\theta_{r}=42.66 \%$, $q=0.83, c=24.65$, and $d=24.39$.

Figure 11 shows the three-dimensional fitting results using equation (12) for the two kinds of expansive soil. It can be seen that the initial dry density, matric suction, and volumetric water content all affect each other, and the test points are all near the fitting model surface, indicating that the Gardner model has a good fitting effect.

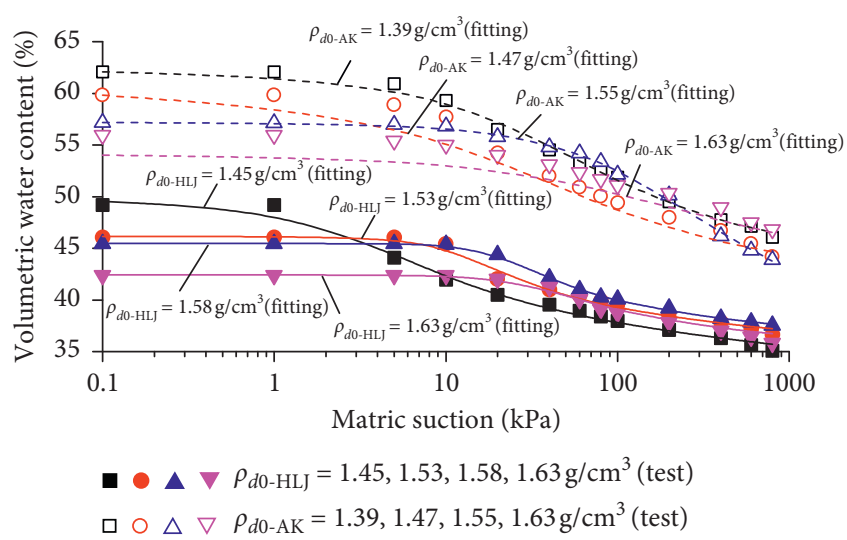

FIgUre 9: The fitting curves using Gardner model under different initial dry densities.

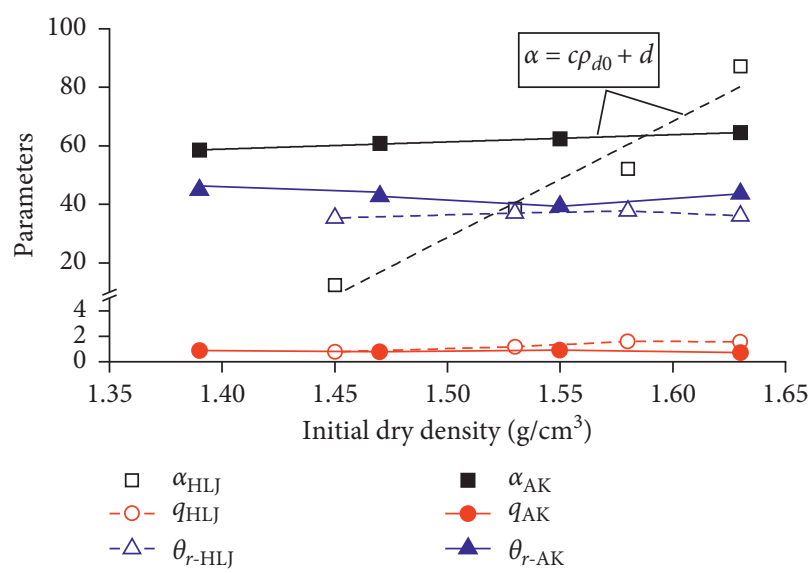

FIgURE 10: Relationships between parameters of Gardner model and the initial dry density for HLJ soil.

5.2. Model Fitting of SWCC considering the Dry-Wet Cycle. Similarly, the fitting curves of the Gardner model for the two expansive soils under different times of dry-wet cycle are shown in Figure 12. It can be seen that the Gardner model can better characterize the soil-water characteristics of HLJ and AK expansive soil under different times of dry-wet cycle.

Figure 13 shows the relationships between Gardner model parameters and time of the dry-wet cycle of two expansive soils. It can be seen that the variation law of fitting parameters of expansive soil in different areas is different. The parameter $\alpha$ and the time of dry-wet cycle of AK soil can be expressed by the power function approximately. And the other parameters have little change with the time of dry-wet 


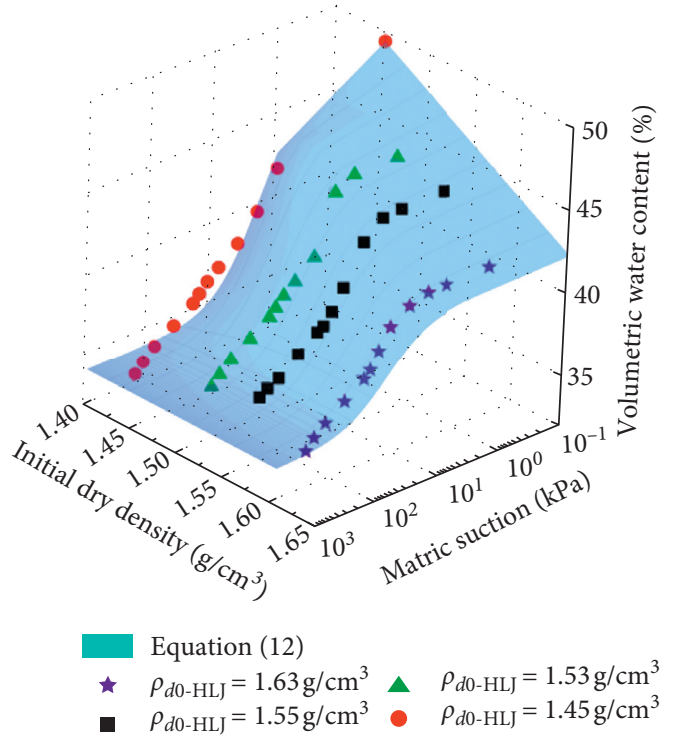

(a)

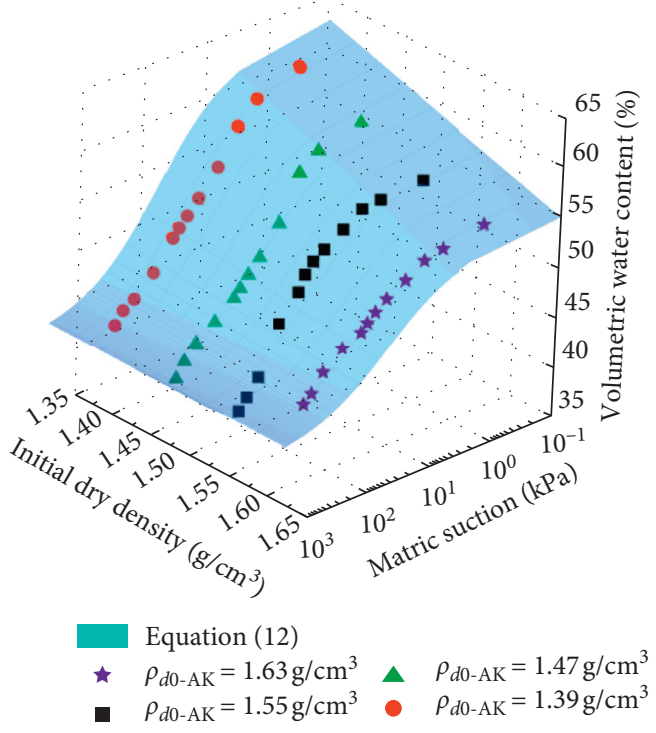

(b)

Figure 11: The three-dimensional fitting results under different initial dry densities: (a) HLJ soil and (b) AK soil.

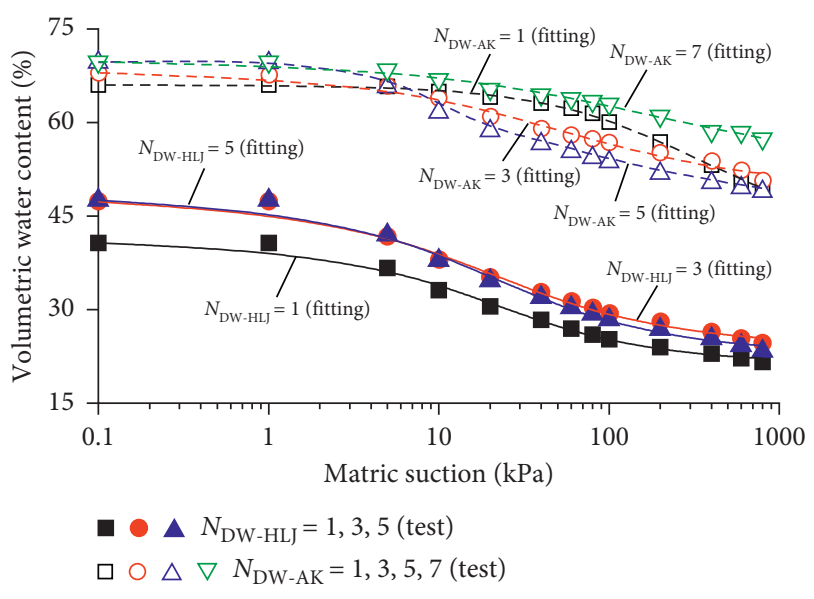

FIGURE 12: The fitting curves using Gardner model under different times of the dry-wet cycle.

cycle $\left(N_{\mathrm{DW}}\right)$, taking the corresponding mean value in the model. By introducing the parameters into the Gardner model, the soil-water characteristic equation of the two expansive soils considering the time of dry-wet cycle can be obtained as follows:

$$
\theta=\theta_{r}+\frac{\theta_{s}-\theta_{r}}{1+(s / \alpha)^{q}}=\theta_{r}+\frac{\theta_{s}-\theta_{r}}{1+\left(s /\left(i N_{\mathrm{DW}}^{j}\right)\right)^{q}}
$$

where for HLJ soil, $\theta_{r}=23.03 \%, q=0.85$, and $\alpha=19.74$; for AK soil, $\theta_{r}=46.54 \%, q=0.83, i=144.51$, and $j=-0.85$.

Figure 14 is the three-dimensional fitting results of SWCC using equation (13) for two kinds of expansive soil under different times of the dry-wet cycle. It can be seen that the test points of 7 times of dry-wet cycle of AK expansive soil are relatively discrete in the high matric suction stage.

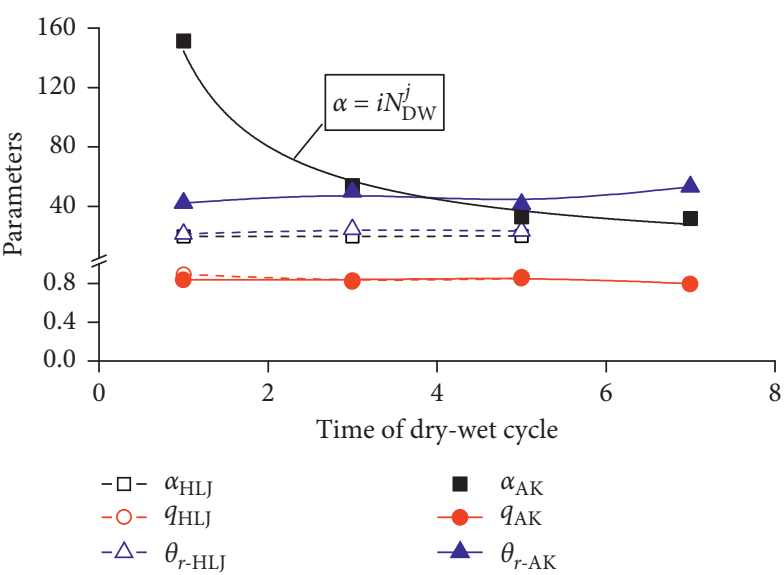

FIgURE 13: Relationships between parameters of Gardner model and the time of the dry-wet cycle.

The SWCCs within the 5 times of dry-wet cycle $\left(N_{\text {DW }}\right)$ are all above and below the fitting model surface, which indicates that equation (13) can better represent the SWCCs of expansive soil under certain dry-wet cycles $\left(N_{\mathrm{DW}} \leq 5\right)$.

5.3. Model Fitting ofSWCC considering the Freeze-Thaw Cycle. Figure 15 shows the fitting curves using the Gardner model for AK expansive soil under different times of the freezethaw cycle. It can be seen that the test points are near the corresponding fitting curves, which indicates that the Gardner model has a higher fitting degree for the test points.

Figure 16 shows the relationships between Gardner model parameters and time of freeze-thaw cycle for $\mathrm{AK}$ expansive soil. It can be seen that with the increase of time of freeze-thaw cycle, the residual volumetric water content $\left(\theta_{r}\right)$ and parameter $q$ have a little change, so their mean value can 


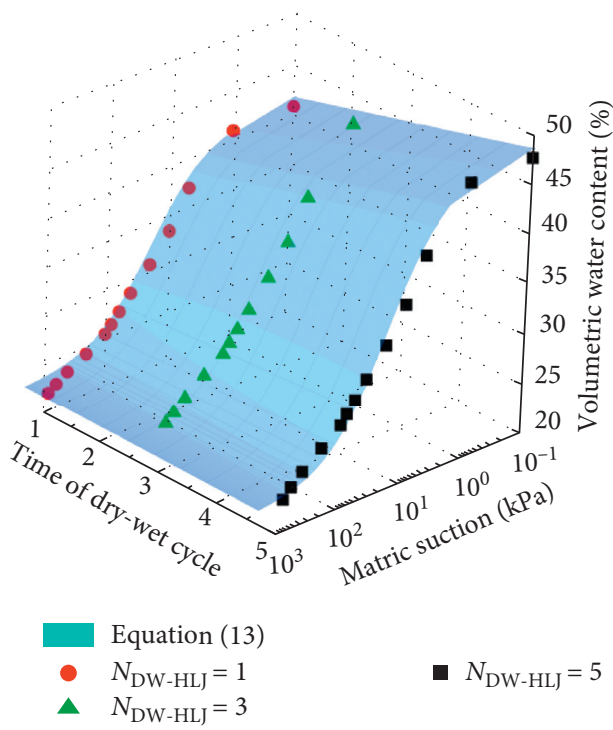

(a)

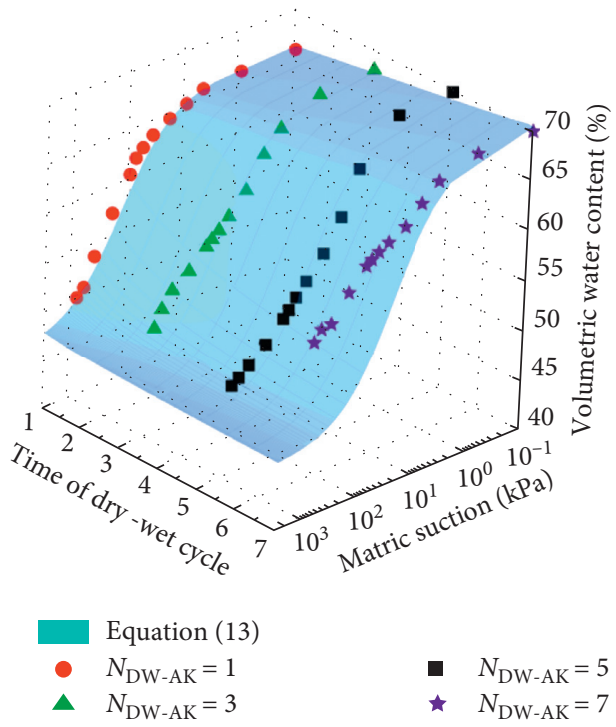

(b)

FIgURE 14: The three-dimensional fitting results of SWCC under different times of dry-wet cycle: (a) HLJ soil and (b) AK soil.

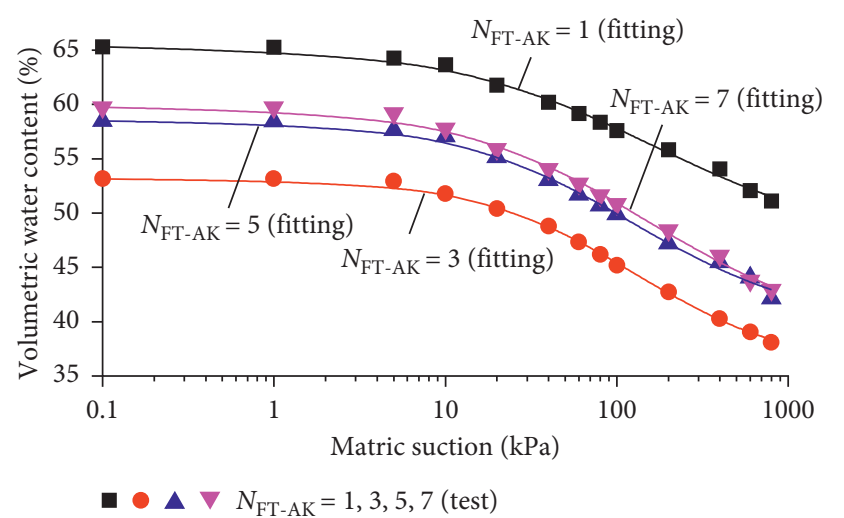

FIgURE 15: The fitting curves using Gardner model under different times of freeze-thaw cycle for AK expansive soil.

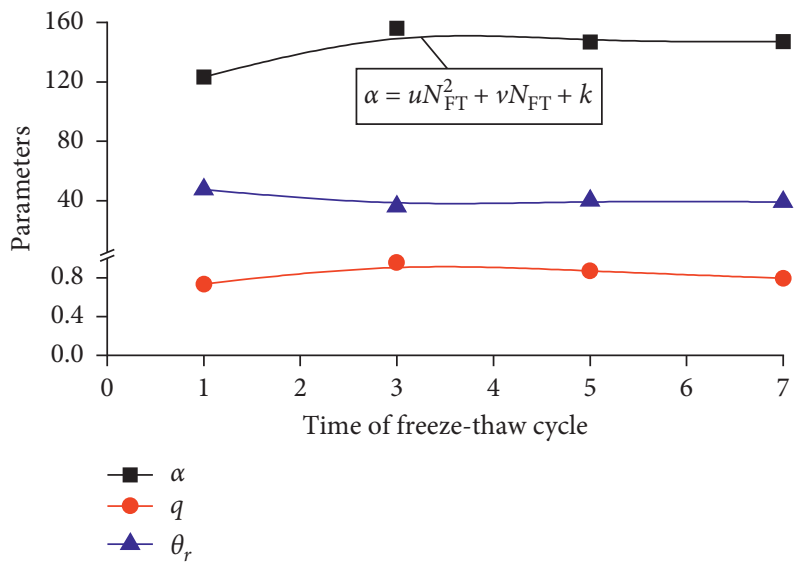

FIGURE 16: Relationships between parameters of the Gardner model and the time of freeze-thaw cycle. be used in the model. The parameter $\alpha$ first increases and then decreases and tends to be stable. After the 3 times of freezethaw cycle, the parameter $\alpha$ is the largest, which indicates that after a certain freeze-thaw cycle, the particles in the sample are rearranged, and the structure is reconstructed to a secondary stable stage. A polynomial equation is used to reflect the effect of the freeze-thaw cycle on parameter $\alpha$; the corresponding Gardner model expression is as follows:

$$
\theta=\theta_{r}+\frac{\theta_{s}-\theta_{r}}{1+\left(s /\left(u N_{\mathrm{FT}}^{2}+v N_{\mathrm{FT}}+k\right)\right)^{q}},
$$

where for AK soil, $\theta_{r}=40.55 \%, q=0.84, u=-2.02, v=19.29$, and $k=108.64$.

Figure 17 shows the three-dimensional fitting results of SWCC using equation (14) for AK expansive soil under different times of times of freeze-thaw cycle. It can be seen that the test points with the time of freeze-thaw cycle greater than one $\left(N_{\mathrm{FT}} \geq 1\right)$ are all near the fitting model surface, indicating that equation (14) is more suitable for the soil-water characteristics under the influence of the certain freeze-thaw cycle.

\section{Discussion}

In addition to the swelling and shrinkage deformation caused by the change of water content, the samples under the action of centrifugal force will also produce different degrees of shrinkage in the centrifuge test. Therefore, in addition to the previous correction method (Section 3.2) based on the shrinkage test, it can also be modified based on the centrifuge test.

6.1. Correction Method Based on the Centrifuge Test. Some studies have shown that there is no obvious transverse shrinkage in the SWCC test [35]. Therefore, only the vertical 


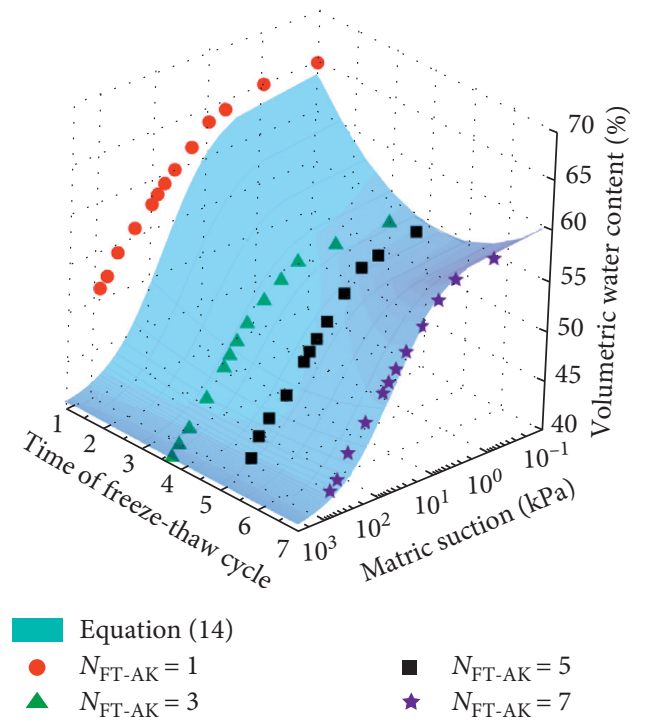

FIGURE 17: The three-dimensional fitting results under different times of freeze-thaw cycle for AK soil.

shrinkage is measured after water balance at each stage centrifugal force ignoring the transverse shrinkage, so as to obtain the density of the sample. Equations (15)-(17) are used to correct the volumetric water content successively based on the centrifuge test.

$$
\begin{aligned}
\rho^{\prime} & =\frac{m^{\prime}}{V_{0}\left(1-\left(\Delta Z / Z_{0}\right)\right)^{\prime}} \\
\rho_{d} & =\frac{\rho^{\prime}}{1+w^{\prime}}, \\
\theta & =\rho_{d} w^{\prime},
\end{aligned}
$$

where $\rho^{\prime}$ is the density of the sample after balancing at each centrifugal force $\left(\mathrm{g} / \mathrm{cm}^{3}\right) ; m^{\prime}$ is the quality of the sample after balancing $(\mathrm{g}) ; \rho_{d}$ is the dry density of the sample after balancing $\left(\mathrm{g} / \mathrm{cm}^{3}\right) ; w^{\prime}$ is the water content of the sample after balancing (\%).

6.2. Comparison of Two Correction Methods. Figure 18 shows the SWCCs before and after volume correction by two methods under different initial dry densities, taking HLJ expansive soil as an example. The following can be seen:

(1) No matter which correction method is adopted, under the same initial dry density and matrix suction, the modified volumetric water content is higher than that before correction, and the higher the matrix suction is, the more obvious the difference is. This is the result of considering the volume shrinkage of expansive soil. During the process of dehumidification of expansive soil, the volume shrinks to a certain extent with the decreasing of water, and the water contained in the pore is relatively high.
Therefore, the SWCCs will move up as a whole after considering the shrinkage deformation of expansive soil. In addition, the higher the initial dry density, the higher the air intake value, and the better the waterholding capacity. The reason is that the larger the initial dry density, the denser the sample; less internal pores result in the less water discharged under the action of centrifugal force and the worse air and water permeability of the sample. This is the same as the conclusion obtained by other scholars with the filter paper method and pressure plate method [22].

(2) The comparison between the two correction methods shows that there is little difference between the two methods in the low matrix suction region, and the modified curve based on the centrifuge test is above that of the shrinkage test in the high matrix suction region. The modified method based on the shrinkage test is to measure the vertical shrinkage coefficient by shrinkage test. Based on the assumption that the transverse and vertical shrinkage coefficients of the samples are approximately equal, the volumetric strain and volumetric water content of the sample are calculated by considering the transverse and vertical volumetric strains during the shrinkage due to loss of water, and the calculation results are more accurate. The modified method based on the centrifuge test is to use the vernier caliper to directly measure the vertical shrinkage deformation after balancing at each stage matrix suction. Due to the disturbance of the sample when opening the centrifuge tube to take out the sample and the influence of loose particles on the surface of the sample, the measurement accuracy is relatively low. In conclusion, it is reasonable to correct the SWCC based on the shrinkage test in this paper. 


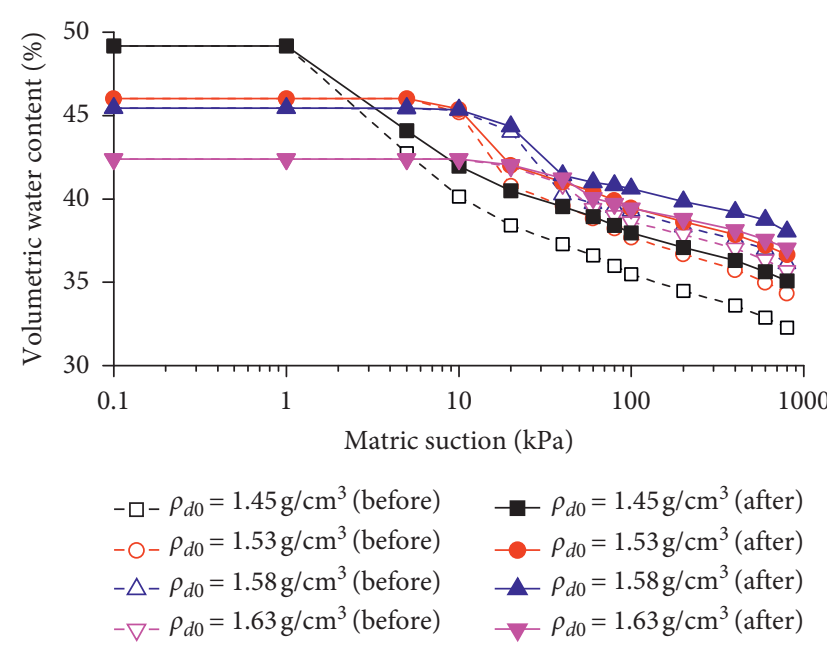

(a)

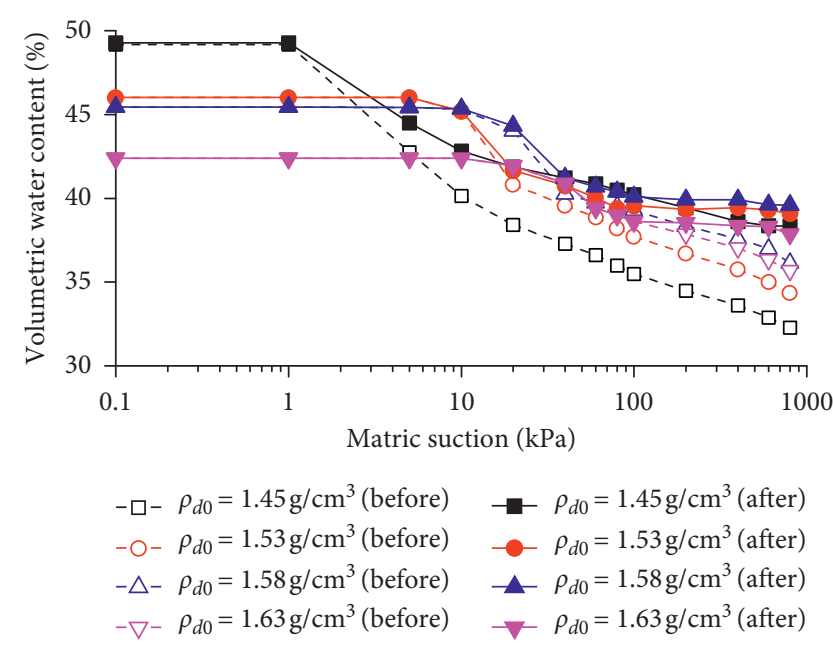

(b)

FIGURE 18: Relationships between volumetric water content and matrix suction after correction (a) based on the shrinkage test and (b) based on the centrifuge test.

\section{Conclusions}

In this paper, the SWCCs of expansive soil in Heilongjiang and Ankang areas were measured by the centrifuge method under different dry densities and times of dry-wet cycle and freeze-thaw cycle. Considering the shrinkage effect of expansive soil, the volumetric strain of SWCC was modified, and the soil-water characteristics under different conditions were explored. The main conclusions are as follows:

(1) Two correction methods based on the shrinkage test and centrifuge test are used to correct the SWCC of expansive soil. The volumetric water content after correction is higher, and the difference is large in the higher matric suction section. In comparison with the centrifuge test for correction, the correction method based on the shrinkage test is more accurate.

(2) With the increase of initial dry density, the vertical shrinkage coefficient, the water-holding capacity, and the air intake value all increase; however, the saturated volumetric water content decreases. With the increase of the time of dry-wet cycle, the saturated volumetric water content increases, and the water-holding capacity decreases obviously. With the increase of the time of freeze-thaw cycle, the saturated volumetric water content first decreases and then increases. However, when the time of drywet or freeze-thaw cycle increases to a certain extent, the structure of the samples gradually becomes stable and the corresponding parameters change slowly.

(3) The SWCCs of expansive soil under different initial dry densities and times of dry-wet cycle and freeze-thaw cycle were fitted based on the Gardner model, and the fitted equations considering the influence of various factors are given, which provide a certain reference for the study of mechanical properties such as seepage and rainfall infiltration in expansive soil areas.

\section{Data Availability}

The data used to support the findings of this study are available from the corresponding author upon request.

\section{Conflicts of Interest}

The authors declare that there are no conflicts of interest regarding the publication of this paper.

\section{Acknowledgments}

The authors are grateful to Associate Professor Minxia Guo for sample preparation, Associate Professor Haijun $\mathrm{Hu}$ for guiding the experimental operation, and teachers WuqingYan and Shunxiang Kang for management and help to the laboratory of Northwest A\&F University. This work was supported by the State Key Research and Development Plan of China (grant no. 2017YFC0405103), the National Natural Science Foundation of China (grant no. 51978572), and the Key Research and Development Projects in Shaanxi Province of China (grant number 2017ZDXM-SF-074). These supports are greatly appreciated.

\section{References}

[1] X. Fu, M. Shao, D. Lu, and H. Wang, "Soil water characteristic curve measurement without bulk density changes and its implications in the estimation of soil hydraulic properties," Geoderma, vol. 167-168, pp. 1-8, 2011.

[2] S. E. Vero, M. G. Healy, T. Henry et al., "A methodological framework to determine optimum durations for the construction of soil water characteristic curves using centrifugation," Irish Journal of Agricultural and Food Research, vol. 55, no. 2, pp. 91-99, 2016.

[3] H. Rahardjo, X. F. Nong, D. T. T. Lee, E. C. Leong, and Y. L. Fong, "Expedited soil-water characteristic curve tests using combined centrifuge and chilled mirror techniques," Geotechnical Testing Journal, vol. 41, no. 1, pp. 207-217, 2018. 
[4] Y. G. Wang, A. J. Zhang, W. Y. Ren, and L. S. Niu, "Study on the Soil Water characteristic curve and its fitting model of Ili loess with high level of soluble salts," Journal of Hydrology, vol. 578, pp. 1-10, 2019.

[5] L. Li, X.-A. Li, L. Wang, B. Hong, J. Shi, and J. Sun, "The effects of soil shrinkage during centrifuge tests on SWCC and soil microstructure measurements," Bulletin of Engineering Geology and the Environment, vol. 79, no. 7, pp. 3879-3895, 2020.

[6] A. Ghorbani, H. Hasanzadehshooiili, M. Mohammadi et al., "Effect of selected nanospheres on the mechanical strength of lime-stabilized high-plasticity clay soils," Advances in Civil Engineering, vol. 2019, Article ID 4257530, 11 pages, 2019.

[7] A. M. Al-Mahbashi, M. Al-Shamrani, and A. Moghal, "Soilwater characteristic curve and one-dimensional deformation characteristics of fiber-reinforced lime-blended expansive soil," Journal of Materials in Civil Engineering, vol. 32, no. 6, pp. 1-9, 2020.

[8] J. James and P. K. Pandian, "Plasticity, swell-shrink, and microstructure of phosphogypsum admixed lime stabilized expansive soil," Advances in Civil Engineering, vol. 2016, Article ID 9798456, 10 pages, 2016.

[9] J. James and P. K. Pandian, "Bagasse ash as an auxiliary additive to lime stabilization of an expansive soil: strength and microstructural investigation," Advances in Civil Engineering, vol. 2018, Article ID 9658639, 16 pages, 2018.

[10] A. Al-Taie, M. Disfani, R. Evans, A. Arulrajah, and S. Horpibulsuk, "Volumetric behavior and soil water characteristic curve of untreated and lime-stabilized reactive clay," International Journal of Geomechanics, vol. 19, no. 2, pp. 1-13, 2019.

[11] Z. C. Zhu, D. A. Sun, A. N. Zhou, and Z. H. Qiu, "Calibration of two filter papers at different temperatures and its application to GMZ bentonite," Environmental Earth Sciences, vol. 75, no. 6, pp. 1-11, 2016.

[12] Z. Han, S. K. Vanapalli, and W.-1. Zou, "Integrated approaches for predicting soil-water characteristic curve and resilient modulus of compacted fine-grained subgrade soils," Canadian Geotechnical Journal, vol. 54, no. 5, pp. 646-663, 2017.

[13] M. Ito and S. Azam, "Engineering properties of a vertisolic expansive soil deposit," Engineering Geology, vol. 152, no. 1, pp. 10-16, 2013.

[14] A. J. Puppala, T. Manosuthikij, and B. C. S. Chittoori, "Swell and shrinkage characterizations of unsaturated expansive clays from Texas," Engineering Geology, vol. 164, no. 1, pp. 187-194, 2013.

[15] A. J. Puppala, K. Punthutaecha, and S. K. Vanapalli, "Soilwater characteristic curves of stabilized expansive soils," Journal of Geotechnical and Geoenvironmental Engineering, vol. 132, no. 6, pp. 736-751, 2006.

[16] T. Y. Elkady, A. M. Al-Mahbashi, and T. O. Al-Refeai, "Stressdependent soil-water characteristic curves of lime-treated expansive clay," Journal of Materials in Civil Engineering, vol. 27, no. 3, pp. 1-9, 2015.

[17] Z. Han and S. K. Vanapalli, "Stiffness and shear strength of unsaturated soils in relation to soil-water characteristic curve," Géotechnique, vol. 66, no. 8, pp. 627-647, 2016.

[18] B. C. Zhou and L. W. Kong, "Effect of volume changes on soilwater characteristics of unsaturated expansive soil," Journal of Hydraulic Engineering, vol. 39, no. 10, pp.1152-1160, 2011, (in Chinese).

[19] W. L. Zou, J. F. Zhang, and X. Q. Wang, "Volume change correction and soil-water characteristics of remodeling expansive soil under dehydration path," Chinese Journal of Geotechnical Engineering, vol. 34, no. 12, pp. 2213-2219, 2012, (in Chinese).
[20] Y.-x. Ye, W.-1. Zou, Z. Han, and X.-w. Liu, "Predicting the entire soil-water characteristic curve using measurements within low suction range," Journal of Mountain Science, vol. 16, no. 5, pp. 1198-1214, 2019.

[21] T. Ma, C. Wei, C. Yao, and P. Yi, "Microstructural evolution of expansive clay during drying-wetting cycle," Acta Geotechnica, vol. 15, no. 8, pp. 2355-2366, 2020.

[22] D. A. Sun and D. J. Huang, "Soil-water and deformation characteristics of Nanyang expansive soil after wetting-drying cycles," Rock and Soil Mechanics, vol. 36, no. S1, pp. 115-119, 2015, (in Chinese).

[23] J. Zhang, D. A. Sun, A. Zhou, and T. Jiang, "Hydromechanical behaviour of expansive soils with different suctions and suction histories," Canadian Geotechnical Journal, vol. 53, no. 1, pp. 1-13, 2016.

[24] L. Miao, S. Liu, and Y. Lai, "Research of soil-water characteristics and shear strength features of nanyang expansive soil,” Engineering Geology, vol. 65, no. 4, pp. 261-267, 2002.

[25] H. Ye, C. Chu, L. Xu, K. Guo, and D. Li, "Experimental studies on drying-wetting cycle characteristics of expansive soils improved by industrial wastes," Advances in Civil Engineering, vol. 2018, Article ID 2321361, 9 pages, 2018.

[26] J. James, P. K. Pandian, S. Chidambaram, B. Dayanandan, and K. Karthick, "Bagasse ash as an auxiliary additive to lime stabilization of an expansive soil: strength and microstructural investigation," Advances in Civil Engineering, vol. 2018, Article ID 9658639, 16 pages, 2018.

[27] S. H. Wang, Q. Z. Wang, J. L. Qi, and F. Y. Liu, "Experimental study on freezing point of saline soft clay after freeze-thaw cycling," Geomechanics and Engineering, vol. 15, no. 4, pp. 997-1004, 2018.

[28] J. Xu, Y. F. Li, W. Lan, and S. H. Wang, "Shear strength and damage mechanism of saline intact loess after freeze-thaw cycling," Cold Regions Science and Technology, vol. 164, pp. 1-13, 2019.

[29] Q. Z. Wang, J. L. Qi, S. H. Wang, J. Xu, and Y. G. Yang, "Effect of freeze-thaw on freezing point of a saline loess," Cold Regions Science and Technology, vol. 170, pp. 1-21, 2020.

[30] H. Zhang, S. Y. Chen, and H. L. Yao, "Estimation of volumetric water content in the pressure plate test by use of shrinkage test data," Rock and Soil Mechanics, vol. 20, no. 2, pp. 22-26, 1999, (in Chinese).

[31] S. Salager, M. S. El Youssouf, and C. Saix, "Definition and experimental determination of a soil-water retention surface," Canadian Geotechnical Journal, vol. 47, no. 6, pp. 609-622, 2010.

[32] W. R. Gardner, "Some steady-state solutions of the unsaturated moisture flow equation with application to evaporation from a water table," Soil Science, vol. 85, no. 4, pp. 228-232, 1958.

[33] M. T. van Genuchten, "A closed-form equation for predicting the hydraulic conductivity of unsaturated soils," Soil Science Society of America Journal, vol. 44, no. 5, pp. 892-898, 1980.

[34] D. G. Fredlund and A. Xing, "Equations for the soil-water characteristic curve," Canadian Geotechnical Journal, vol. 31, no. 4, pp. 521-532, 1994.

[35] X. G. Xing, W. G. Zhao, X. Y. Ma, and Y. L. Zhang, "Study on soil shrinkage characteristics during soil water characteristic curve measurement," Journal of Water Conservancy, vol. 46, no. 10, pp. 1181-1188, 2015, (in Chinese). 